\title{
Screw driving sounding test; a new technology in soil investigation work particularly for soft soil
}

\author{
Aminaton Marto ${ }^{1,2, *}$, Go Sakai ${ }^{3}$, Naoaki Suemasa ${ }^{4}$, Nor Zurairahetty Mohd Yunus ${ }^{5}$, Siti \\ Norafida Jusoh ${ }^{5}$, Kamarudin Ahmad ${ }^{5}$, and Muhammad Hatta Mohd Satar ${ }^{5}$ \\ ${ }^{1}$ Malaysia-Japan International Institute of Technology, Universiti Teknologi Malaysia, Kuala \\ Lumpur, Malaysia \\ ${ }^{2}$ Centre of Tropical Geoengineering (GEOTROPIK), Universiti Teknologi Malaysia, Johor, Malaysia \\ ${ }^{3}$ Japan Home Shield Corporation, Tokyo, Japan \\ ${ }^{4}$ Department of Urban and Civil Engineering, Tokyo City University, Tokyo, Japan \\ ${ }^{5}$ School of Civil Engineering, Universiti Teknologi Malaysia, Johor, Malaysia
}

\begin{abstract}
Screw Driving Sounding (SDS) test has been developed in Japan as the improved version of the Swedish Weight Sounding (SWS) test. The development of SDS is to reduce the drawbacks of the SWS with the integration of rod friction estimation. Deep boring with Standard Penetration Tests (SPT) together with soil sampling for laboratory tests have been the common procedure for determining the subsurface soil profile and geotechnical engineering properties. However, the SPT which is associated with deep boring, uses high fossil fuels, needs high skilled workers and expensive. This paper presents the SDS technology and the SDS test results in comparison with the existing SPT data from six (6) selected sites in Malaysia. Results show that there is a strong correlation between SPT and SDS data, and the soil profile is better identified using SDS than the SPT. It is predicted that SDS test has the potential to replace conventional soil investigation methods, particularly in soft soils area. It is not just fast, cheap and does not require highly skilled workers but SDS tests supports green technology and sustainability in construction. Quality results are guaranteed from the usage of Industrial Revolution 4.0 technology through automation in testing and making use of the cloud computing to manage the data.
\end{abstract}

\section{Introduction}

Soil investigation is crucial in the construction process, and it needs to be done to prevent catastrophic events or massive damage to occur in the future. It is quite common that laboratory classification samples, retrieved from boreholes are used as a conventional method to determine the soil stratigraphy. However, the conventional method is cumbersome due to time-consuming and high cost. Therefore, with the advancement of technology; the use of in-situ soil testing has increased in geotechnical engineering practice

* Corresponding author: aminaton@utm.my 
to provide economical alternatives with the consideration to sustainability in construction. This is due to the rapid development of in-situ instruments which improved better understanding regarding soil behavior, the limitations, and inadequacies of some conventional laboratory testing [1].

In conjunction with the above, there is several in-situ soil testing that is available for the characterization of the soils. For instances, the most commonly tests; Standard Penetration Test (SPT), Cone Penetration Test (CPT), Piezo-cone (CPTu), Swedish Weight Sounding (SWS), Flat Dilatometer Test (DMT), Pressuremeter Test (PMT), and Vane Shear Test (VST) [2-5] Each test applies specific loading patterns to measure the corresponding soil response in an attempt to evaluate material characteristics, such as strength and/or stiffness [6]. SPT in particular, have some limitations such as the need of at least three workers and a long time to complete one test even though it can determine reasonably certain soil characteristics. Since SPT has to be carried out through deep boring that uses large drilling machine, the work process uses a lot of fossil fuel which is not sustainable to the environment. Particularly for SWS, the method has been explained clearly by $[5,7,8]$.

A soil investigation equipment named as the Screw Driving Sounding (SDS), had been developed together by Tokyo City University, Japan Home Shield Corporation (JHS) and Nitto Seiko Co. Ltd. Only one person can carry the SDS test and uses minimal energy to operate $[5,7,8]$. Also, it can determine various parameters for soil classification and properties purposes without extruding the sample for laboratory tests. This method is best used to investigate the soils with SPT-N values of less than 15 [9]. However, it is vital to prove that SDS technique is useful as well as can provide an accurate reading regarding the soil characteristics which previously have been identified by the SPT method. Also, there is a significant gap in knowledge related to the suitable parameter used via this technique. Hence, it will significantly contribute as one of the methods which can be applied in the process of soil investigation if a valid correlation between SDS and SPT could be achieved.

Universiti Teknologi Malaysia (UTM) had signed a Memorandum of Agreement (MoA) to undertake the Joint Research and Development of SDS tests between UTM and Japan Home Shield Corporation (JHS) in 2017. This is the first attempt of using SDS in site investigation work in Malaysia. The research had been assisted by the team in Japan and New Zealand including the JHS itself, Nitto Seiko Co. Ltd. as the manufacturer of SDS equipment, Tokyo City University and Auckland University, New Zealand, as the first organization to do SDS tests and research outside Japan. The sites chosen are mainly for housing development and road or highway projects. The study was aimed at developing the correlation between properties of soils in Malaysia obtained from conventional soil drilling using the underground boring machine (particularly the SPT) and the Mackintosh probe, with the results obtained using SDS tests from ten (10) sites. However, this paper presents the SDS test results and the correlations of SDS and SPT data for various soil types, obtained from six (6) sites.

\section{Screw driving sounding equipment, theoretical assumption, test method and analysis method}

\subsection{The technology of screw driving sounding equipment}

Based on the manufacturer's manual [9], the SDS equipment is known as Geokarte III SDS type F in which the machine combined the SWS and SDS tests. Hence, the operator may choose either to carry out SWS or SDS test to suit the requirement of the SI work. (SWS has been a famous SI test for the construction of the low-rise building in Japan). The machine's parts are as shown in Fig. 1 and when already assembled, it is as shown in Fig. 2. 
SDS equipment has the characteristics of; automated test and record, reduces hard work and work efficiency, excellent safety structure, and the build block structure is easy to carry. The transport and test modes of SDS equipment are as shown in Fig. 3. SDS equipment can be directly put on the soil surface or top of a crawler for easy mobility.

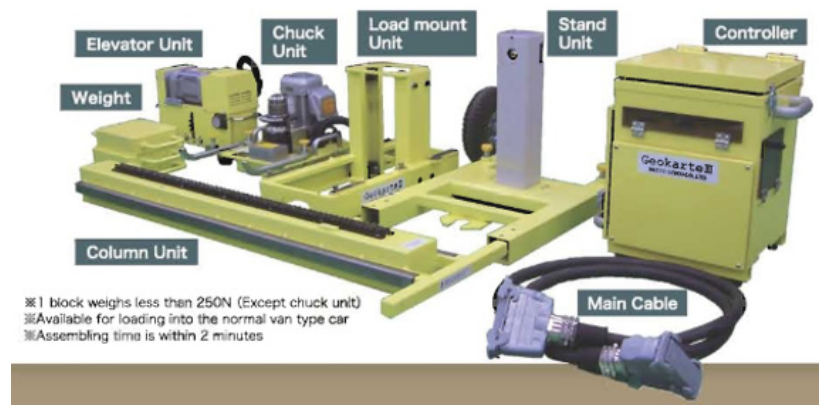

Fig. 1. Parts of Screw Driving Sounding equipment [9].

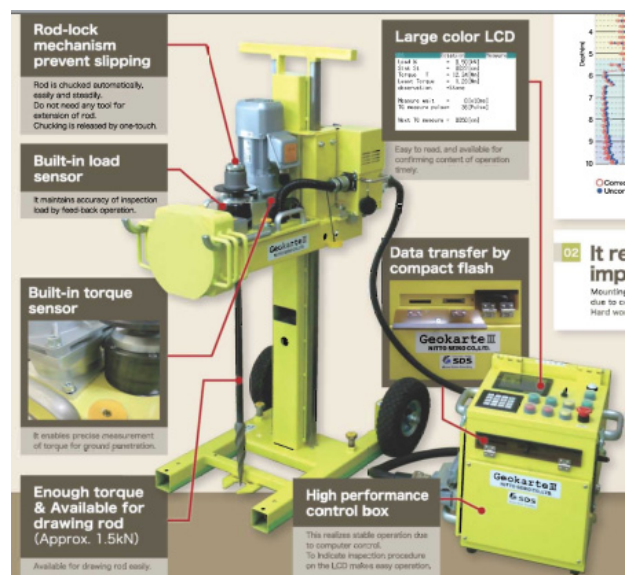

Fig. 2. Screw Driving Sounding equipment after being assembled [9].

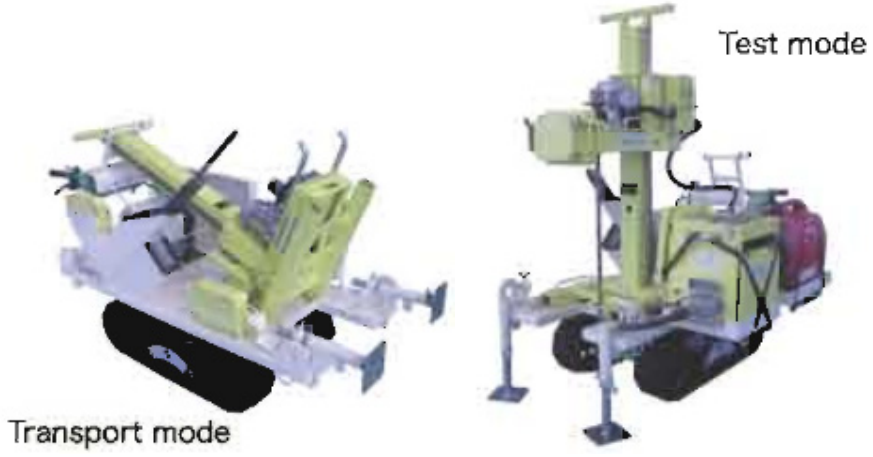

Fig. 3. Transport and test mode of Screw Driving Sounding equipment [9].

\subsection{Theoretical assumption}

A plasticity model for the SDS test has been proposed by [10] from the results of SDS miniature tests and illustrated by [11] in Fig. 4 . The combination of torque and vertical load 
measured in the SDS test forms a yield locus and the corresponding incremental components of a rotation rate, and the settlement rate obeys the potential plastic rule [12]. The interactive relationship between the combined loads and the corresponding displacement of the soil element had been described as a constitutive equation.

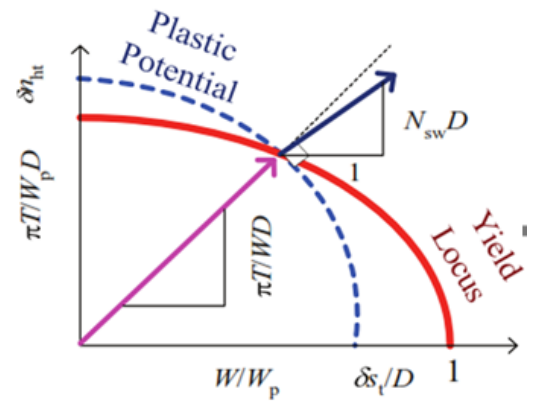

Fig. 4. Concept of plasticity model for SDS [11].

\subsection{Test and analysis methods}

The SDS test method has been widely explained by previous researchers such as $[5,8,12-$ 15] Basically SDS test uses 7 number of load steps and the rod would penetrate the soil layer continuously at the rate of $25 \mathrm{rpm}$. The 7 load steps for SDS are $0.25,0.38,0.50,0.63$, $0.75,0.88$ and $1 \mathrm{kN}$. The load is increased for every revolution of the rod. For each $250 \mathrm{~mm}$ penetration, the rod will move up about 10 to $20 \mathrm{~mm}$ and rotate back down to calculate the rod friction. The concept of estimating rod friction has been explained by [7]. When the rod penetrates the ground while being rotated during the SDS test, two components of rod friction occurred, which are a vertical component, Wf, and a horizontal component, Tf. The frictions are measured after each $250 \mathrm{~mm}$ penetration when the rod is lifted about 10 to 20 $\mathrm{mm}$ and then rotated back to the previous position. Through the Eqn. (1) and Eqn. (2) Below, the corrected torque, $\mathrm{T}$ and corrected load, $\mathrm{W}$ at the screw point are calculated for each $250 \mathrm{~mm}$ penetration. It is necessary to deduct the friction to obtain the actual force applied to the rod.

$$
\begin{aligned}
& \mathrm{W}_{\mathrm{a}}=\mathrm{W}_{\mathrm{f}}+\mathrm{W} \\
& \mathrm{T}_{\mathrm{a}}=\mathrm{T}_{\mathrm{f}}+\mathrm{T}
\end{aligned}
$$

in which $\mathrm{W}_{\mathrm{a}}$ and $\mathrm{T}_{\mathrm{a}}$ are applied load and applied torque, respectively.

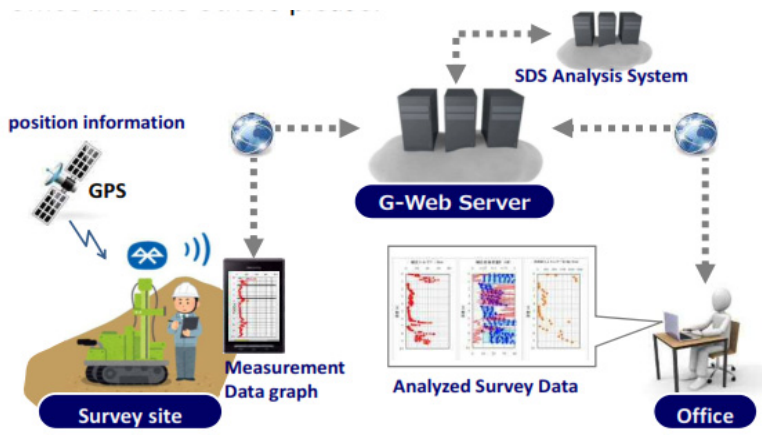

Fig. 5. Geo-web system in capturing, storing and analyzing the SDS data. 
Upon completion of the test, the data that automatically captured by the SDS machine could be sent to the 'cloud' system (Geo-web system) and would be later downloaded for further analysis. Once results are forwarded to the Geo-web system, anyone with the given password could access the analyzed data. While the test crew is still at the site, one could instruct them to do more tests if upon checking through Geo-web system it shows questionable or contradictory results. This is the technology in line with the Industrial Revolution 4.0 that is by using automation in work and making use of the cloud computing technology [8]. The Geo-web system in capturing, storing and analyzing the SDS data is shown in Fig. 5.

\subsubsection{Correlating SDS data and SPT-N value}

A regression analysis was done by [15] on the results between SDS and SPT in order to provide a relationship of both. SDS-N value or $\mathrm{N}_{\mathrm{SDS}}$ had been developed from an Eq. (3):

$$
N_{S D S}=\alpha_{1} \times d T / d s_{t}+\alpha_{2} \times E_{0.25}+\alpha_{3} \times C_{n l}+\alpha_{4}
$$

where $N_{S D S}=$ predicted SPT blow count from SDS test, $\alpha=$ constants from regression analysis, $d T / d s_{t}=$ slope torque with penetration amount, $E_{0.25}=$ energy for total penetration of $25 \mathrm{~cm}, C_{n l}=$ coefficient of non-linearity with increase tendency of penetration energy.

Graphs of $\mathrm{N}_{\mathrm{SPT}}$ value and $\mathrm{N}_{\mathrm{SDS}}$ was plotted by [15] to get a correlation between two tests for sandy and clayey soils shown in Fig. 6. From both of the graphs, the correlation is approximately 0.62 , which is an acceptable correlation [15].

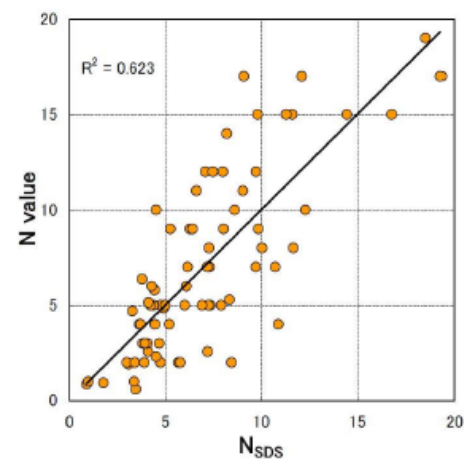

(a)

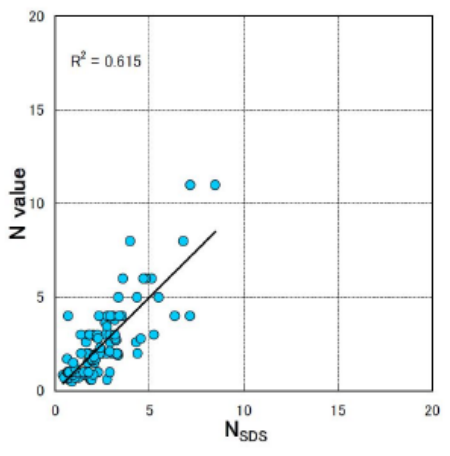

(b)

Fig. 6. Correlation of N value vs NSDS (a) sandy soil (b) clayey soil [15].

The correlations between the data obtained from SDS tests had been carried out with SPT-N values by researchers in Japan and New Zealand to determine the relationship from both tests. This is necessary if SDS test is aimed at replacing SPT tests in the future because the design of shallow foundation, in particular, is generally using SPT-N value besides the strength parameters obtained from laboratory tests. The attempt on the correlation is through determining the relationship between the SPT-N value and the E0.25, the data acquired from the SDS test. E0.25 is a parameter related to energy, which is the sum of the work done by the corrected load (EW) and the work by the corrected torque (ET) when the rod is penetrated to $25 \mathrm{~cm}$ depth at each loading section. E0.25 is used as a good indicator of soil layer stiffness as the $\mathrm{N}$ value in SPT $[8,16,17]$.

For estimation of SPT-N value, the soil type was first determined from the data in the SI report. Next, a graph comparison between $\mathrm{E}_{0.25}$ and corrected torque with depth was drawn. This is to show that the trend of both data is the same when compared to ensure a good 
correlation between both. Fig. 11 shows an example of comparison between $\mathrm{E}_{0.25}$ and corrected torque done by [4]. [7] reported that the correlation between $\mathrm{E}_{0.25}$ and SPT-N value for Japan soils is $\mathrm{E}_{0.25}=0.268 \mathrm{~N}_{\mathrm{SPT}}$ while in New Zealand, [4] obtained the correlation between $\mathrm{E}_{0.25}$ and $\mathrm{SPT} \mathrm{N}$ value for sandy soil as $\mathrm{E}_{0.25}=0.34 \mathrm{~N}_{\mathrm{SPT}}$.
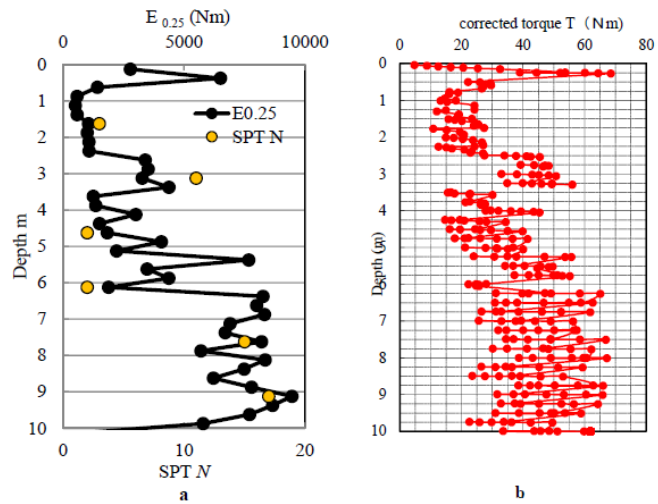

Fig. 11. Comparison of trendline of $\mathrm{E}_{0.25}$ and corrected torque with depth [4].

\subsubsection{Classification of soil using SDS data}

Based on previous studies (e.g. $[12,13,15]$ ), various parameters would be taken into account in analyzing data. From the SDS test, the results obtained are corrected load, torque, and speed of penetration at every $25 \mathrm{~cm}$. The torque required for the screw point to be able to drill into the soil will increase screw point resistance. When a hard layer is reached, the penetration velocity will decrease. Other than that, data such as normalized half turns (NSDD) for every $25 \mathrm{~cm}$ gives the torque required to twist the rod. As mentioned earlier, E0.25 is the energy needed to penetrate $25 \mathrm{~cm}$ of the soil layer, which also indicates the stiffness of soil.

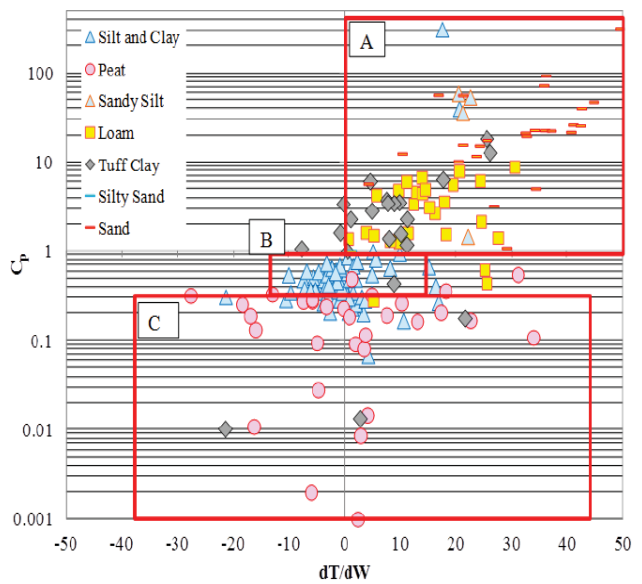

Fig. 12. Relationship between $\mathrm{Cp}$ and $\mathrm{dT} / \mathrm{dW}[7]$.

In Japan, the soil was characterized based on the corrected load graph (dT/dW). It has been proposed by [7] that if the slope value of the corrected torque against the corrected load $(\mathrm{dT} / \mathrm{dW})$ is positive, the soil is considered as sand or loam. On the other hand, if the return value is negative or zero; the soil is identified as clay and silt. The slope of the 
corrected torque also depends on the density and soil friction. A higher value of $\mathrm{dT} / \mathrm{dW}$ indicates that the site is experiencing denser materials with high friction. The coefficient of plastic potential (Cp') is an indication of the difficulty of penetration. From the Japanese database, the appropriate range of $\mathrm{Cp}$ ' values for different types of soils is as follows: sand layer: $>1$; silt and clay: $0.3-1$; and peat and organic soil: $<0.3$. These two coefficients dT/dW and Cp', have a relation to defining a better soil type as shown in Fig. 12 for soils in Japan [7].

In a more current publication, based on SDS data from 25 sites, the soils in Japan has been classified by [12] through a "Soil Classification Chart" shown in Fig. 13. From the plot of Cp' versus the change of normalised torque to change of corrected load, dT/dWD, the soil types in Japan are identifed as Clay, Silt, Sandy Clay, Loam and Peat. Cp' varies from 0.1 to 10 while the $\mathrm{dT} / \mathrm{dWD}$ spans from -1.5 to 1.5 .

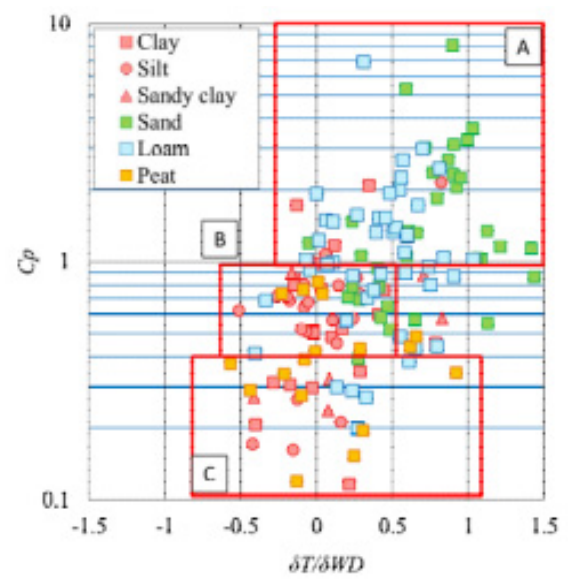

Fig. 13. Soil classification chart for soils in Japan [12].

For soils in New Zealand, almost the same chart has been produced by [13], as shown in Fig. 14. Seven types of soils in New Zealand; Clay, Stiff Peat, Plastic Clay, Silty Clay, Clayey Silt, Sand, Sandy Silt, Silty Sand and Silt had been classified in the chart.

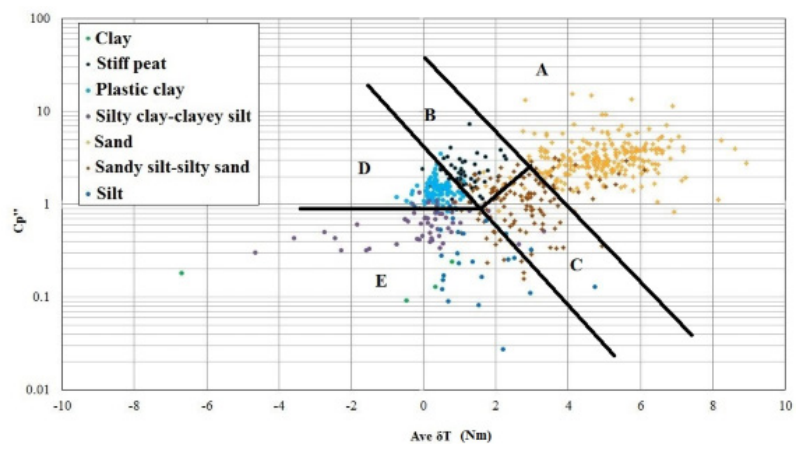

Fig. 14. Soil classification chart for soils in New Zealand [5].

\section{SDS field tests and obtained data}

In providing soil characterizations and site profiling in Malaysian soil and geology, the first attempt was to carry out SDS tests at ten sites around Johor, Kuala Lumpur, and Selangor. The sites are comprised of various types of soil and formation. Results of SPT and 
laboratory tests of boring in-depth investigation from the SI Reports of selected sites were analyzed and used to compare with the SDS results. For this paper, however, only the results from six (6) sites were able to be used in obtaining SDS correlations with SPT data and in achieving the Soil Classification Chart. SDS test points were carried out within 1.5 $\mathrm{m}$ to $2 \mathrm{~m}$ around the $\mathrm{BH}$ point. The SDS test sites location is as shown in Fig. 15 while Fig. 16 shows photos of the SDS tests carried out by the research team.

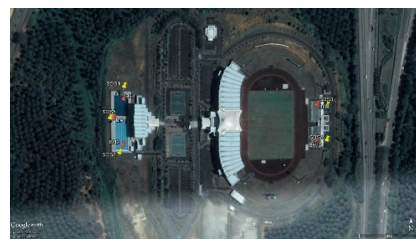

(a)

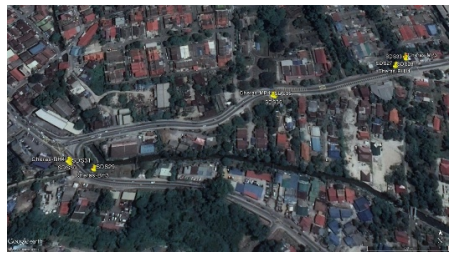

(d)

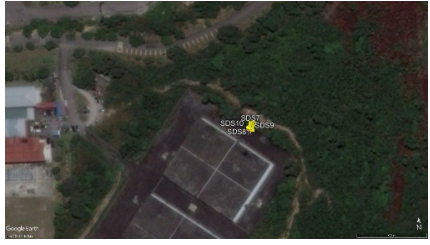

(b)

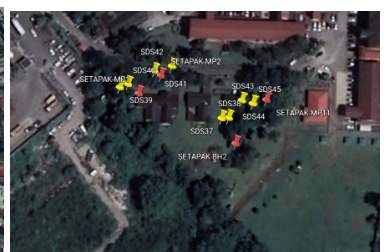

(e)

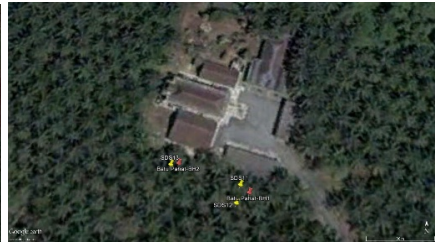

(c)

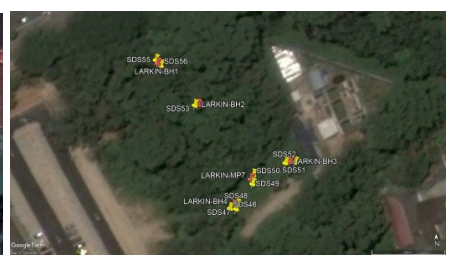

(f)

Fig. 15. Site locations for SDS tests (a) UTM Stadium, (b) Pasir Gudang, (c) Batu Pahat, (d) Cheras, (e) Setapak, (f) Larkin.

The data from each site were downloaded from Geo-web system. The analyzed data was put in excel spreadsheets which comprised of depth, corrected load, corrected torque and penetration energy. Then the borehole records from deep boring using rotary drilling, consisting of the soil profile, Standard Penetration Test as well as the sieve and Atterberg limit laboratory tests results, were used to compare with SDS test data. Using the spreadsheet, E0.25 was calculated at every $25 \mathrm{~cm}$ penetration to be correlated with SPT-N values.
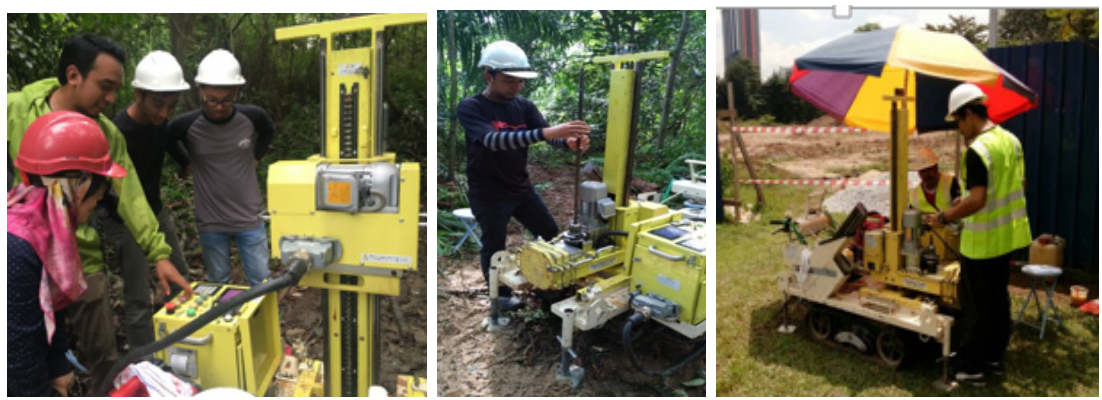

Fig. 16. SDS tests at selected sites.

\section{Results and discussion}

\subsection{Identification of soil profile}

The soil profile of each investigated site was plotted alongside with the corrected torque obtained from SDS tests. Fig. 17 shows examples of SDS results in comparison to the soil 
profile obtained from the bore logs of SI report at Pasir Gudang and Cheras. From the SDS test, the corrected torque variations with depth are compared with the soil profile from deep boring work. It could be deduced that the variations of corrected torque are large for stiff soils while sand tends to have a larger variety of corrected torque when compared with clay. This is attributable to sand having large particles causing high friction which is shown through a high SPT-N value. Hence, this indicates that corrected torque can classify different soil types with different strength. The boundary of each soil layers could also be identified more clearly by SDS test since it is a continuous test, unlike SPT as it is carried out at a specific depth interval. This can be seen in Fig. 17.

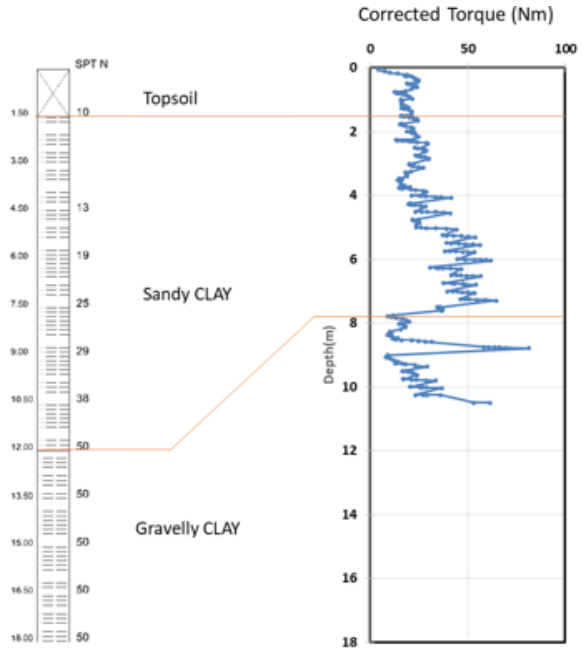

(a)

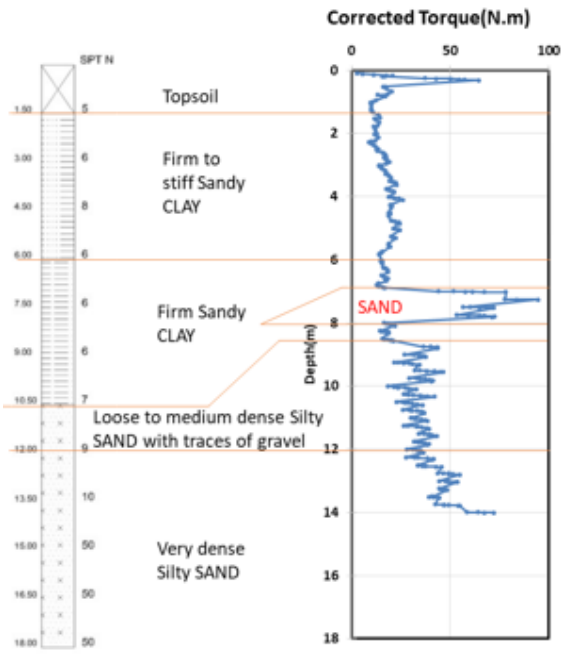

(b)

Fig. 17. Soil profile from borehole record compared to SDS data from Pasir Gudang and Cheras sites (a) Pasir Gudang (BH5, SDS7), (b) Cheras (BHJ1, SDS 28).

From the plot of corrected torque with depth, thin layers of soil such as sand can be detected. As shown in Fig. 17(b) a thin layer of sand is identified at Cheras site from 6.75 to $8 \mathrm{~m}$ depth. Sand layers are identified through the shape of corrected torque developed at each $25 \mathrm{~cm}$ penetration. At this layer, the value of corrected torque increased with penetration depth at each seven steps load increment due to high friction as a result of the screw point going through the frictional soils. This phenomena, recognized in the SDS test, has also been explained by [13]. Since this is a thin layer, investigation through deep boring using SPT was not able to identify its existence. On the other hand, torque is consistent with depths when SDS penetrates through clayey or silty soils due to none or limited frictional materials within the layer besides due to undrained situation resulted with zero friction angle.

\subsection{Correlation between SPT and SDS data}

The data obtained from SDS and SPT were correlated to determine a relationship between both tests. The SPT-N value was correlated with the $\mathrm{E}_{0.25}$ data acquired from SDS which is similar to the method done by [7] and described by [8] and [16]. Fig. 18 shows an example of $\mathrm{E}_{0.25}$ together with Cp' and dT/dWD with depth for a site in Pasir Gudang.

The $\mathrm{E}_{0.25}$ had been plotted against SPT-N values for all sites as shown in Fig. 19. From the Fig. 19 it is found that the coefficient of determination, $\mathrm{R}^{2}$ for the relationship between SPT-N value and $E_{0.25}$ is 0.71 (coefficient of correlation, $R$ is 0.84 ) which shows that $71 \%$ 
of $\mathrm{E}_{0.25}$ is dependent on SPT-N. Hence this is considered as a very good correlation since SDS test result (in terms of $\mathrm{E}_{0.25}$ ) is highly correlated with SPT-N values despite the limited data obtained. From the linear regression analysis shown in Fig. 18, the $\mathrm{E}_{0.25}$ is found to be correlated with SPT-N value $\left(\mathrm{N}_{\mathrm{SPT}}\right)$ as follows:

$$
\mathrm{E}_{0.25}=0.183 \mathrm{~N}_{\mathrm{SPT}}
$$

By separating the soil types accordingly from each site the results of E0.25 and respective SPT-N values for each soil types were used to determine the correlations between SDS test and SPT results. The soils are grouped into three types of soils which are Sandy, Clayey and Silty since there were too limited data for some of the soil types which makes it impossible to correlate each or individual soil type. For the grouping, Sandy soils include Sand, Silty Sand, Sandy Silt and Sandy Clay, and Silty soils include Silt, Clayey Silty, and Sandy Silt while Clayey soils include Clay, Silty Clay, Sandy Clay, and Gravelly Clay. Results of correlation between SDS test and SPT are shown in Fig. 20 for Sandy, Clayey and Silty soils. From the linear regression analysis, the E0.25 is found to be correlated with SPT-N value (NSPT) as shown in Equations (5) to (7) for sandy, clayey and silty soils, respectively.
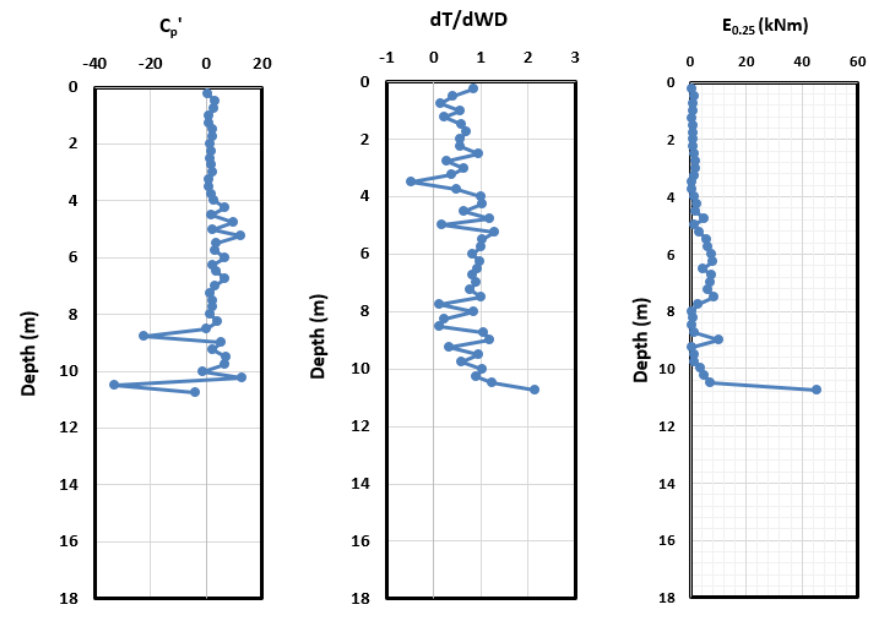

Fig. 18. Variations of $\mathrm{E}_{0.25}, \mathrm{Cp}$ ' and dT/dWD with depth for Pasir Gudang Site.

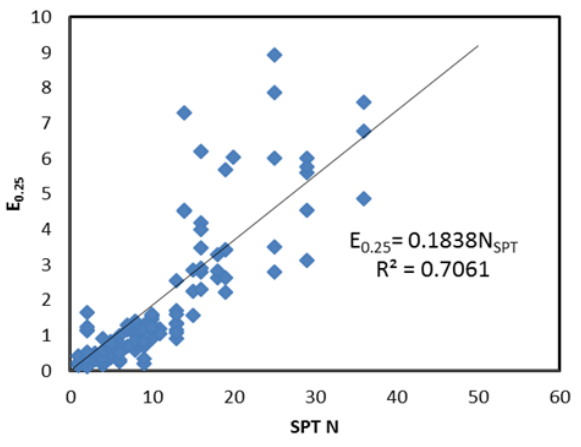

Fig. 19. Correlation between E 0.25 obtained from SDS test and SPT-N value for all soil types.

From the results shown in Fig. 20, it can be seen that the correlation obtained for Clayey soil is quite similar with Sandy soil probably due to the nature of the clayey soil which is similar with 'loam' in Japan. Loam, as reported by [12], falls into a similar quadrant as sand 
in the Cp' versus dT/dWD plot of Japan soils. Based on the value of $\mathrm{R}^{2}$ greater than and equals to 0.6 , it can be said that all correlations show the goodness of fit. This is because $60 \%$ or more of variation in $\mathrm{E}_{0.25}$ is explained by SPT-N value.

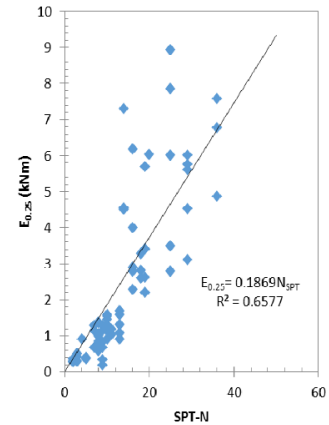

(a) Sandy soils

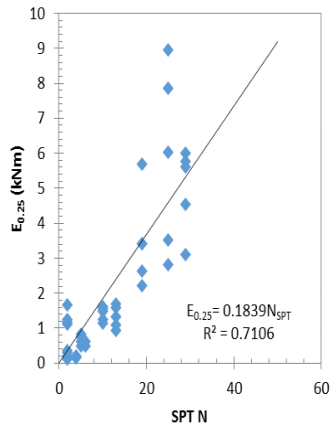

(b) Clayey soils

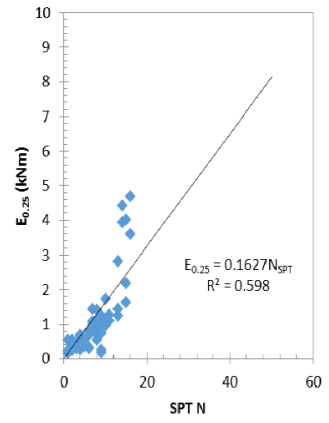

(c) Silty soils

Fig. 20. Correlation between $E_{0.25}$ obtained from SDS test and SPT-N value for sandy, clayey and silty soils.

$$
\begin{array}{ll}
\text { Sandy, } & \mathrm{E}_{0.25}=0.189 \mathrm{~N}_{\mathrm{SPT}} \\
\text { Clayey, } & \mathrm{E}_{0.25}=0.184 \mathrm{~N}_{\mathrm{SPT}} \\
\text { Silty, } & \mathrm{E}_{0.25}=0.163 \mathrm{~N}_{\mathrm{SPT}}
\end{array}
$$

For Sandy soils, $66 \%$ of $\mathrm{E}_{0.25}$ is dependent on SPT-N value. Comparing the result shown for Sandy soils from New Zealand as reported by [5], it has much higher slope value (0.268) than what is obtained from this research (0.189). It shows that less amount of energy is required to penetrate a total of $0.25 \mathrm{~m}$ sandy soils in Malaysia that has the same SPT-N value.

\subsection{Soil classification chart for Malaysian soil}

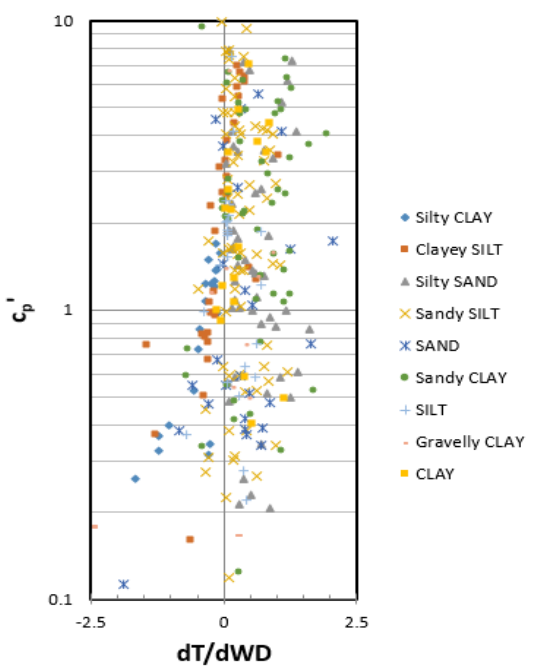

Fig. 21. Soil classification chart for Malaysian soil from selected sites. 
The plots of Cp' against dT/dWD for all results obtained from six sites in this study is shown in Fig. 21. This could be considered as a preliminary Soil Classification Chart for soils in Malaysia. The trend for each soil types could be recognised, and the most obvious is for Sandy soils that occupied the top right-hand side of the graph and also Silt on the lefthand side. This chart, developed from limited data, shows some similarity with soils in Japan and New Zealand.

\section{Conclusions}

The Screw Driving Sounding Tests (SDS) had been performed successfully in soil investigation work of selected sites. Through the experience of carrying out the SDS tests and comparison of the test results with Standard Penetration Test (SPT), some conclusion is drawn as follows. There is a strong correlation between SPT and SDS data, and the soil profile is better identified using SDS than the SPT. Results indicate that SDS is also able to classify the different type of soils found in Malaysia. It is predicted that the SDS test has the potential to replace conventional soil investigation methods, particularly in soft soils area or for low-rise housing and road projects. Through continuous improvement, it is expected that the SDS equipment will also be able to characterize stronger soils, having SPT-N values of greater than 15, soon. SDS test is not just fast, cheap and does not require highly skilled workers but it also supports sustainability based on minimal energy usage to operate, much less than SPT that uses large drilling machine in deep boring. Hence, the implementation of SDS in soil investigation work promotes sustainable development. Quality results from SDS test are guaranteed since the method uses Industrial Revolution 4.0 technology through automation in testing and data capturing, besides making use of the cloud computing system to manage the collected data.

The authors gratefully acknowledge the financial support given by Universiti Teknologi Malaysia through Research University Grant (RUG) No. 16H04 and also the contribution given by the Japan Home Shield Corporation through Research Contract No. 4C134, in undertaking this research. Acknowledgements are also conveyed to respective researchers from the Malaysia-Japan International Institute of Technology (MJIIT) and the School of Civil Eng., Universiti Teknologi Malaysia (UTM) for their assistance. Lastly, the invitation to the first author as an Invited Speaker in ICAnCEE2018 is very much appreciated.

\section{References}

1. A.A. Eslami, A.M. Gholami, J. of Scientia Iranica 13, 3 (2006)

2. C.R.I. Clayton, N.E. Simons, M.C. Matthew, Site investigation (Blackwell Science, Oxford, 1995)

3. J.D. Rogers, J. of Env. Eng. and Geoscience 12, 2 (2006)

4. R. Orense, Y. Mirjafari, N. Suemasa, Japan workshop on soil liquefaction during recent large-scale earthquakes (2013)

5. S.Y. Mirjafari Miandeh, Soil characterisation using screw driving sounding (sds) data (Thesis, University of Auckland, New Zealand, 2016)

6. AASHTO, Manual of Subsurface Investigation (AASHTO, Washington, D.C, 1988)

7. T. Tanaka, N. Suemasa, A. Ikegame, S. Yamato, Int. Soc. Offshore Polar Eng. 4 (2012)

8. A. Marto, G. Sakai, N. Suemasa, N. Jamaludin, Proc. of Int. Conf. on Civil, Offshore \& Environmental Engineering (ICCOEE) (2018) 
9. Nitto Seiko, GeoKarte; New technology machine for SWS and SDS test. Available at: https://www.nittoseiko.co.jp/en/en_products/search/index.php (2016)

10. N. Suemasa, K. Shinkai, T. Suzawa, M. Tamura, Proc. 4th Japan-Philipinnes Workshop on Safety and Stability of Infrastructure, University of Philipinnes (2005)

11. T. Tanaka, N. Suemasa, S. Yamato, T. Katada, Proc. of the $7^{\text {th }}$ International Offshore and polar Engineering Conference (2007)

12. T. Tanaka, N. Suemasa, and S. Yamato, Proc. of Int. Conf. on Soft Ground Engineering (ICSGE) (2015)

13. S.Y. Mirjafari, R.P. Orense, N. Suemasa, Proc. 5th Int. Conf. Geotech. Geophys. Site Characterisation, ISC 2016, 1, 2001 (2016)

14. T. Tanaka, N. Suemasa, S. Yamato, 19th Southeast Asian Geotech. Conf. 2nd AGSSEA Conf. (19SEAGC 2AGSSEA) (2016)

15. Y. Maeda, S. Yamato, G. Sakai, N. Suemasa, T. Tanaka, Proc. 6th International Conf. on Earthquake Geotechnical Engineering, Christchurh, New Zealand (2015)

16. N. Suemasa, T. Tanaka, S. Yamato, G. Sakai, Proc. of International Symposium on Lowland Technology, Hanoi, Vietnam, (2018)

17. S.Y. Mirjafari, R.P. Orense, N. Suemasa, Proc. 5th Int. Conf. Geotech. Geophys. Site Characterisation, ISC 2016, 1, 2001 (2016) 